\title{
THE APPLICATION OF FRICTION STIR PROCESSING TO THE FABRICATION OF MAGNESIUM-BASED FOAMS
}

\begin{abstract}
In the present paper, friction stir processing (FSP) is used to fabricate magnesium-based nanocomposite foams. The effects of the number of FSP passes, $\mathrm{TiH}_{2}$ to $\mathrm{Al}_{2} \mathrm{O}_{3}$ weight ratio, and foaming temperature; on the pore distribution and porosity are described. The results indicate that a minimum $\mathrm{TiH}_{2}$ to $\mathrm{Al}_{2} \mathrm{O}_{3}$ weight ratio is necessary to provide the best pore distribution and porosity. Closed-cell porous magnesium with a porosity of about $17.5 \%$ was successfully fabricated using 4-pass FSP at $800 \mathrm{rpm}$, by adding 5 mass $\% \mathrm{TiH}_{2}$ and 3.5 mass $\% \mathrm{Al}_{2} \mathrm{O}_{3}$; at a holding temperature of $858 \mathrm{~K}$, and a holding time of $45 \mathrm{~min}$.

Keywords: Metal foam, Friction stir processing, Porosity, Magnesium
\end{abstract}

\section{Introduction}

Metallic foams is known to have many interesting physical and mechanical properties, such as high energy absorption and damping capacity, as well as a very low specific weight [1]. In contrast, the potential of magnesium alloys as future structural materials has recently been recognized because of their low specific weight and high damping capacity. Magnesium foams are extremely light weight and highly capable of vibration control. In order to produce magnesium foams, many techniques have been developed, such as powder metallurgy [2-7], molten metal infiltration [8-12], metal foaming [13,14], and metal/gas eutectic unidirectional solidification [15]. However, it is difficult to produce magnesium foams using these conventional manufacturing processes because of the extreme chemical activity of magnesium.

Recently, Hangai and Utsunomiya [16] have developed a new processing route for fabricating a precursor, in which friction stir processing (FSP) is used. FSP is a solid-state process comprising the generation of friction heat and an intense stirring action by inserting and traversing a rotating tool with a probe and a shoulder through the base metal [17]. With the FSP route, the precursor is fabricated by mixing blowing and stabilization agent powders into substrate plates using the significant stirring action of FSP. In this case an inexpensive plate can be used as starting material instead of expensive metal powders, and foaming precursors can be produced using a simple, short process with high productivity. Also, in spite of the bulk foam fabrication process, FSP could produce surface foam in a very selective area where the core of the bulk material is unchanged.

In previous studies on foam fabrication using FSP, porous aluminium (A4045) and porous die casting aluminium alloy
(ADC12) were successfully fabricated [18]. However, there is no report on magnesium foam production using FSP. The aim of the present work was to investigate the possibility of producing magnesium foams using $\mathrm{TiH}_{2}$ and $\mathrm{Al}_{2} \mathrm{O}_{3}$ as blowing and stabilization agents, respectively, with the FSP technique. To this end, the effect of the number of FSP passes, $\mathrm{TiH}_{2}$ to $\mathrm{Al}_{2} \mathrm{O}_{3}$ weight ratio, and foaming temperature on the pore distribution and porosity, were examined.

\section{Experimental procedure}

In this study, pure magnesium castings of a rectangular shape (60 mm wide, $100 \mathrm{~mm}$ long, and $10 \mathrm{~mm}$ thick) was used as a substrate. Titanium hydride $\left(\mathrm{TiH}_{2}, 45 \mu \mathrm{m}\right)$ powders were used as blowing agent and alumina $\left(\alpha-\mathrm{Al}_{2} \mathrm{O}_{3}, 35 \mathrm{~nm}\right)$ powders were used as stabilization agent. The stabilization agent was used to stabilize the pore structure and to prevent the release of gases from porous magnesium by improving the viscosity during the foaming process [19]. Their amounts were 1-5 mass $\%$ for $\mathrm{TiH}_{2}$ and 3.5-5 mass $\%$ for $\mathrm{Al}_{2} \mathrm{O}_{3}$ according to the stir zone of FSP.

The $\mathrm{TiH}_{2}$ and $\mathrm{Al}_{2} \mathrm{O}_{3}$ powders were mixed and fed into a groove (with a width and depth of $1.2 \mathrm{~mm}$ and $5 \mathrm{~mm}$, respectively) that was located on the magnesium castings before FSP. The FSP tool is columnar with a screw probe. The diameter of the tool shoulder was $18 \mathrm{~mm}$. The diameter and length of the tool probe was $6 \mathrm{~mm}$. The tilt angle of $2^{\circ}$ was used. The tool material was H13 hot-work tool steel. The threaded probes had $1 \mathrm{~mm}$ pitch. The tool traversing and rotational speeds were constant values of $150 \mathrm{~mm} / \mathrm{min}$ and $800 \mathrm{rpm}$, respectively. At first, the groove was aligned along the centreline of the rotating probe. At

\footnotetext{
* DEPARTMENT OF MATERIALS SCIENCE AND ENGINEERING, AHVAZ BRANCH, ISLAMIC AZAD UNIVERSITY, AHVAZ, IRAN

** DEPARTMENT OF BASIC SCIENCES, HAMEDAN UNIVERSITY OF TECHNOLOGY, HAMEDAN 65155, IRAN

** DEPARTMENT OF MATERIALS SCIENCE AND ENGINEERING, POHANG UNIVERSITY OF SCIENCE AND TECHNOLOGY (POSTECH), POHANG 790-784, SOUTH KOREA 
the beginning of the FSP, the groove was covered with a modified FSP tool that only had a shoulder and no probe. to prevent the powders from being displaced out of the groove. Then, the tool was inserted into the groove and precursor fabrication was done.

A different number of passes (2-pass, 4-pass, or 6-pass) was applied during FSP to investigate the effect of the number of FSP passes on precursor homogenization. The advancing direction for the subsequent pass was in the opposite direction to the previous pass (i.e. proceeding forward and then backward). The maximum temperature of the surface of the magnesium castings was about $633 \mathrm{~K}$, and was measured using a radiation thermometer. This temperature is below the decomposition temperature of the blowing agent. It is considered that although the microstructure of the precursor is modified by FSP, the melting point is not significantly changed by the altered microstructure of the precursor. Thus, it is assumed that the microstructure of the precursor does not significantly affect the foaming properties.

The FSPed samples containing $\mathrm{TiH}_{2}$ and $\mathrm{Al}_{2} \mathrm{O}_{3}$ were machined to produce precursors of 6-mm thick, 10-mm wide, and $10-\mathrm{mm}$ long. These precursors were heat treated to introduce foaming, in a preheated electric furnace. The holding temperature (equal to the preheated temperature) was constant during the heating process and the holding time was $45 \mathrm{~min}$. Then, the sample was cooled to room temperature under ambient conditions. The holding temperature varied from 828 to $858 \mathrm{~K}$ in steps of $10 \mathrm{~K}$.

Metallurgical inspection was performed on the cross-section of the samples using optical and scanning electron microscopes. The porosity of the foamed magnesium was calculated using image analysis.

\section{Results and discussion}

Figures 1-3 show the cross section of the samples produced under different process parameters. In the precursors which fabricated by FSP, $\mathrm{TiH}_{2}$ and $\mathrm{Al}_{2} \mathrm{O}_{3}$ particles are almost distributed homogeneously. During the foaming treatment, $\mathrm{TiH}_{2}$ decomposed to $\mathrm{Ti}$ and $\mathrm{H}_{2}$. The gas formation of this reaction leads to pores formation. As can be seen in figures 1-3, in all the specimens, some large pores were found in the bottom of the stir zone. According to previous studies on the FSP [20], the material flow is lower in the bottom of the stir zone than near the surface, which
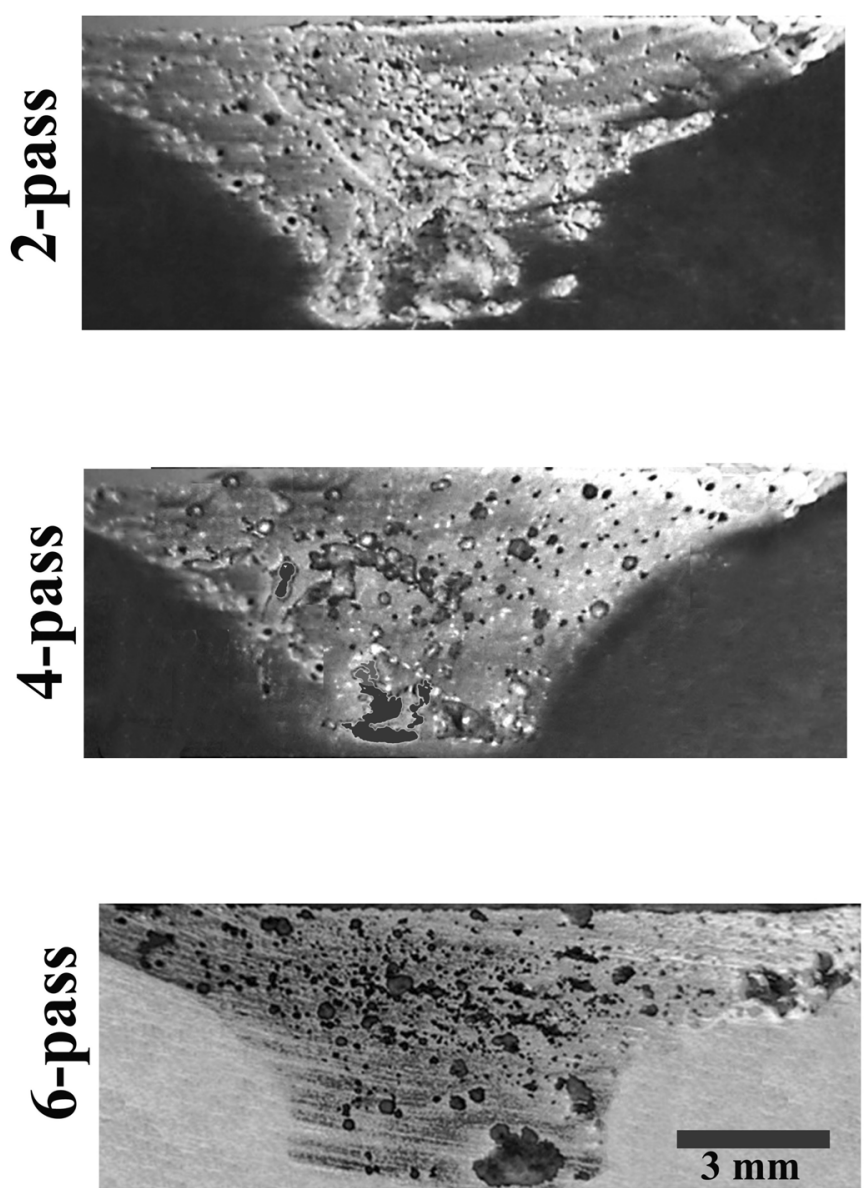

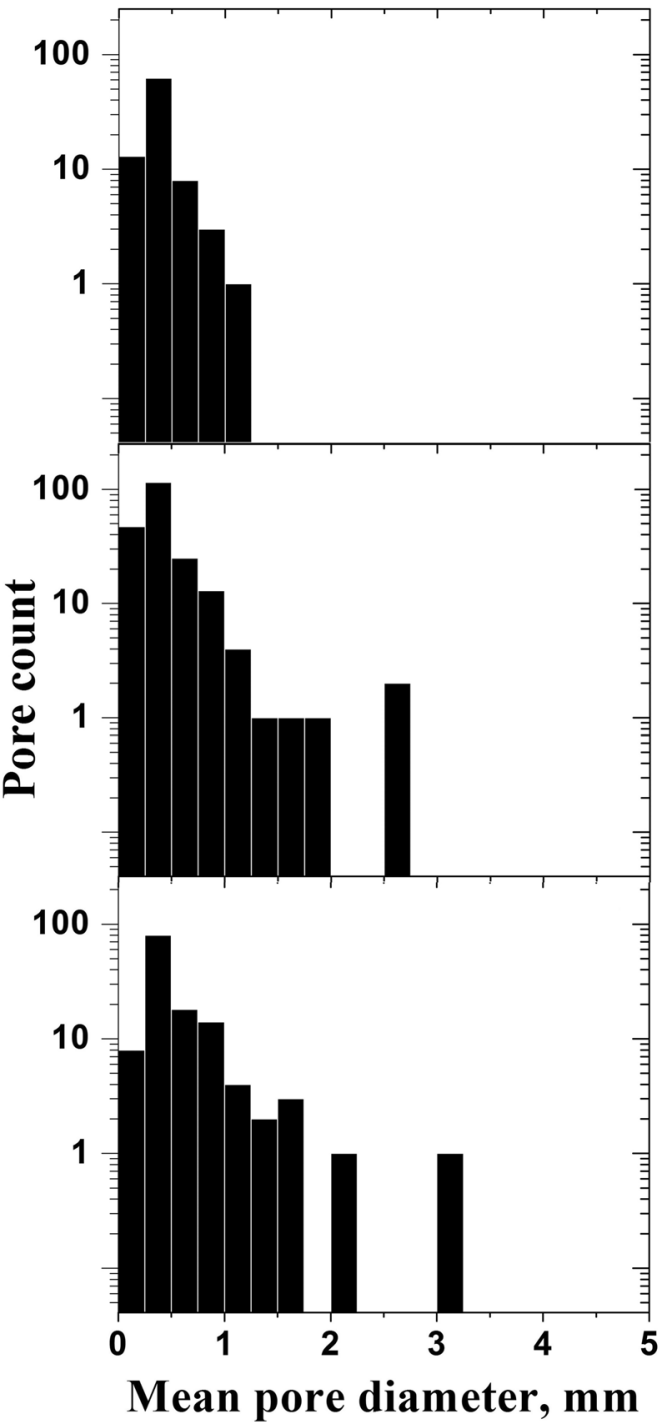

Fig. 1. Effect of the FSP pass number on the pore size and distribution in the samples treated at $858 \mathrm{~K}$ 
is in contact with the tool shoulder. This is due to the strong effect of the shoulder on the material flow. Therefore, inhomogeneous distributions of the $\mathrm{TiH}_{2}$ and $\mathrm{Al}_{2} \mathrm{O}_{3}$ particles occurred in the lower regions. The distribution of the $\mathrm{Al}_{2} \mathrm{O}_{3}$ particles had a major effect on the pore morphology [21]. The pore growth would slow down when the $\mathrm{Al}_{2} \mathrm{O}_{3}$ particles were placed at the matrix/pore interface. Also, the surface of the $\mathrm{Al}_{2} \mathrm{O}_{3}$ particles provides a proper site for pore nucleation. In the bottom of the samples, due to the poor distribution of the $\mathrm{Al}_{2} \mathrm{O}_{3}$ particles, the pores grow rapidly and their coalescence generates large pores.

Figure 1 shows the effect of the number of FSP passes on the pore size and distribution in the sample heat-treated at $858 \mathrm{~K}$. As illustrated, the 4-pass FSP sample exhibited higher porosity than the 2-pass and 6-pass FSP samples. This is due to sufficient and uniform mixing of the $\mathrm{TiH}_{2}$ and $\mathrm{Al}_{2} \mathrm{O}_{3}$ particles into the magnesium base metal in the 4-pass sample. In spite of the low temperature of FSP, due to an increase in diffusion rate by severe plastic deformation, some hydrogen might be released from $\mathrm{TiH}_{2}$ in each FSP pass. As reported in previous work, hydrogen release led to a decrease in the activation energy of hydrogen decomposition of $\mathrm{TiH}_{2}$ [22]. Therefore, further passes could lead to the more generation of pores during the FSP. On the other hand, the severe plastic deformation that occurs during the FSP generates high strain energy in the $\mathrm{TiH}_{2}$ particles, and therefore a lower driving force is needed for hydrogen decomposition. Consequently, more pore nucleation and growth result in
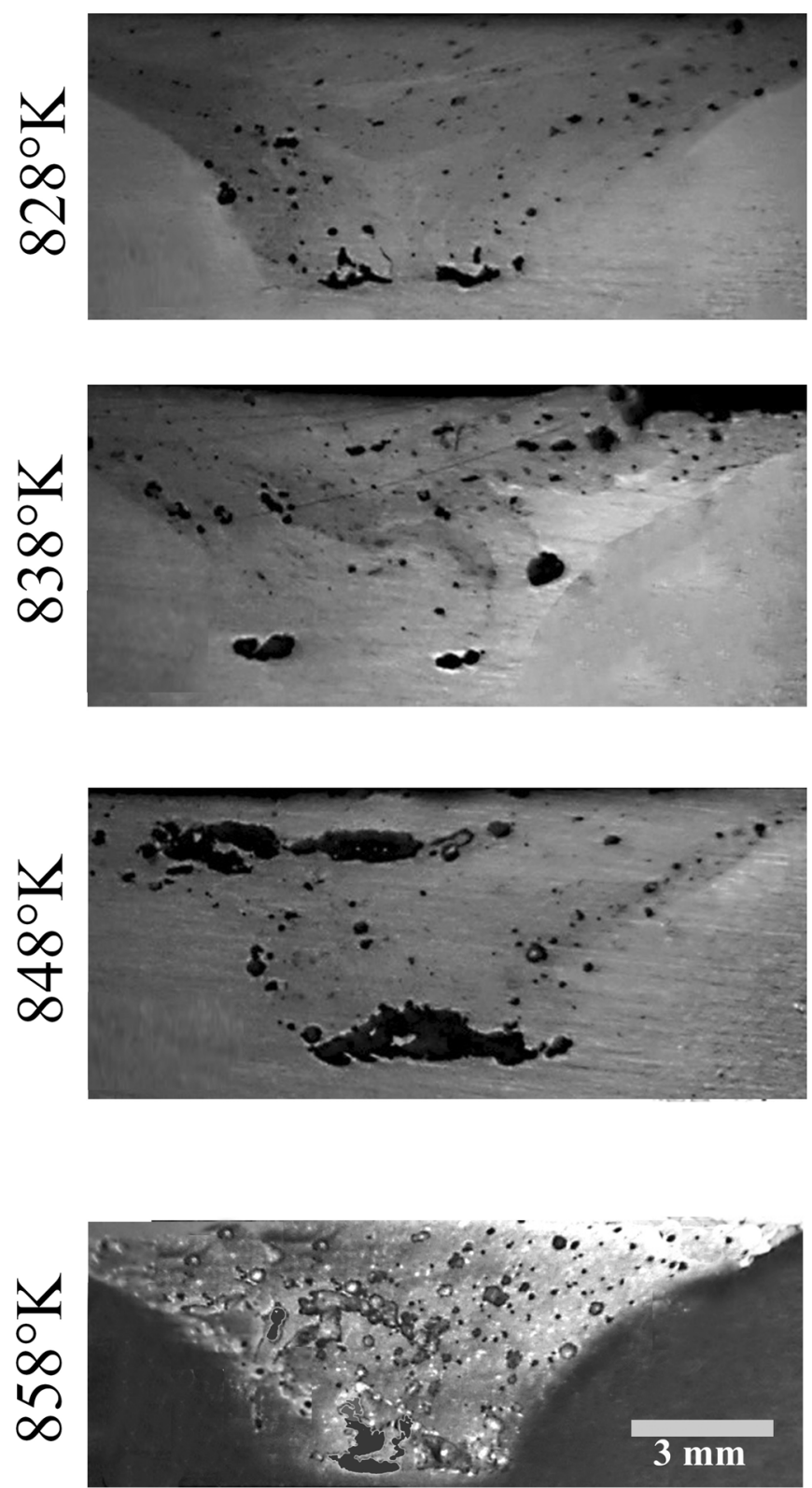

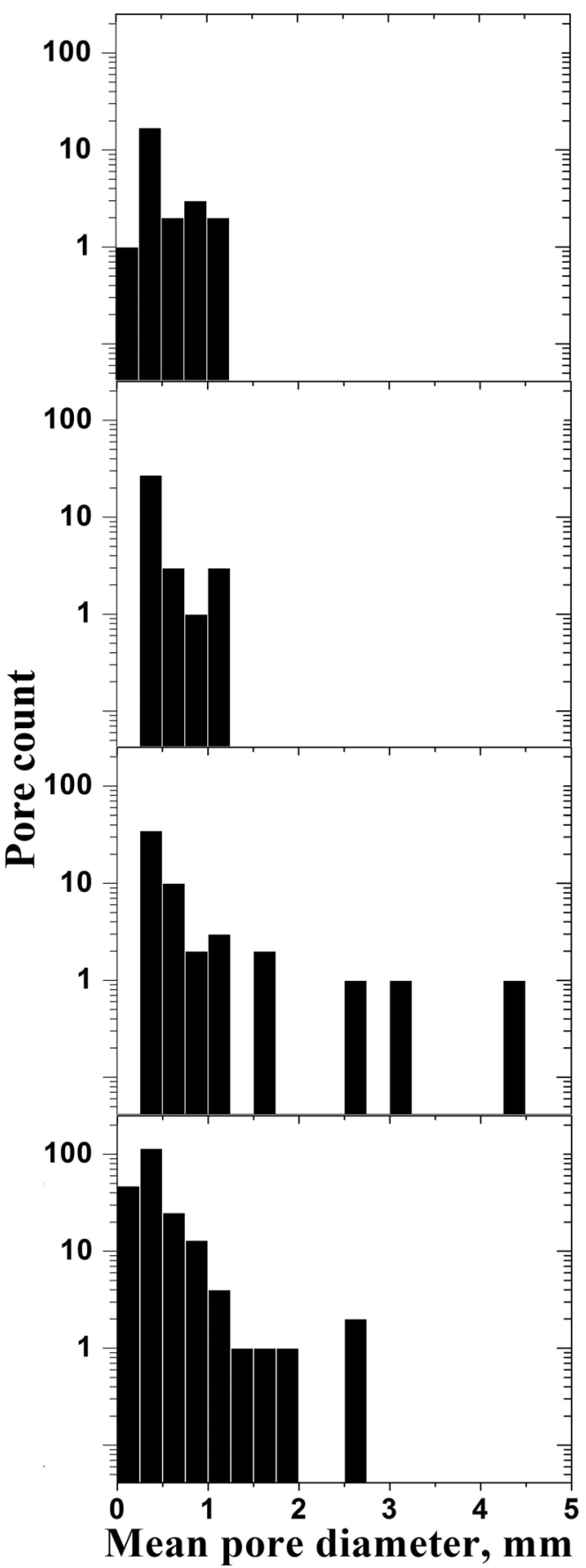

Fig. 2. Effect of the foaming temperature on the pore size and distribution in the 4-pass $\mathrm{FSP}$ samples with $5 \%$ to $3.5 \% \mathrm{TiH}_{2}$ to $\mathrm{Al}_{2} \mathrm{O}_{3}$ weight ratio 
higher porosity. However, in the 6-pass sample, further stirring and heat generation led to pore-coalescence into large pores that collapsed under the FSP tool, resulting in slightly reduced porosity. However, more pore formation improved distribution of the $\mathrm{Al}_{2} \mathrm{O}_{3}$ particles, and decreased the detrimental effect of the pores, which were removed by the stirring action.

As can be seen in Fig. 4, the porosity in the 2-pass specimen is about $2.5 \%$. This value increased to $17.5 \%$ for the 4 -pass specimen, and then decreased to $12.5 \%$ for the 6-pass one. Actually, the porosity for the 6-pass specimen could be higher if pore-collapse did not occur. The increased porosity in the foam fabrication with further passes was also seen in accumulative roll-bonding for fabrication of porous Al4045 alloys [23]. These results indicate that four passes during FSP is necessary to fabricate high-porosity porous magnesium, but further FSP passes decrease the porosity.

Figure 2 shows the morphology of pores in the sample fabricated with four passes at different foaming temperatures. As can be seen, the foaming temperature of $858 \mathrm{~K}$ resulted in the maximum porosity. When the holding temperature was lower, the magnesium matrix was not sufficiently softened for the pores to grow and expand in the magnesium matrix. This tendency is also seen in the powder compact foaming technique [24,25] and the accumulative roll bonding process [26].

Figure 3 shows the effect of the $\mathrm{TiH}_{2}$ to $\mathrm{Al}_{2} \mathrm{O}_{3}$ weight ratio on the pore size and distribution for the samples fabricated using
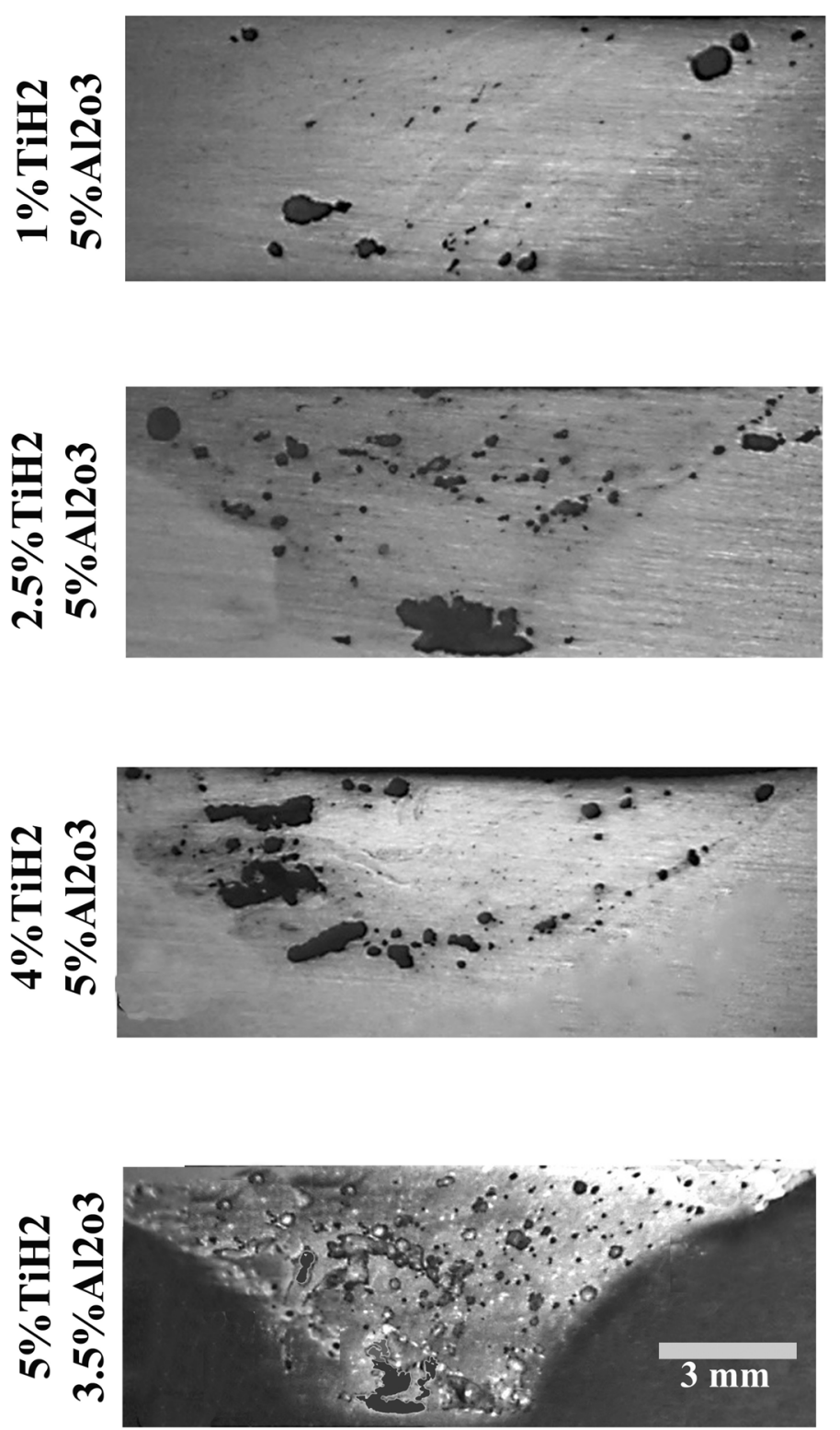

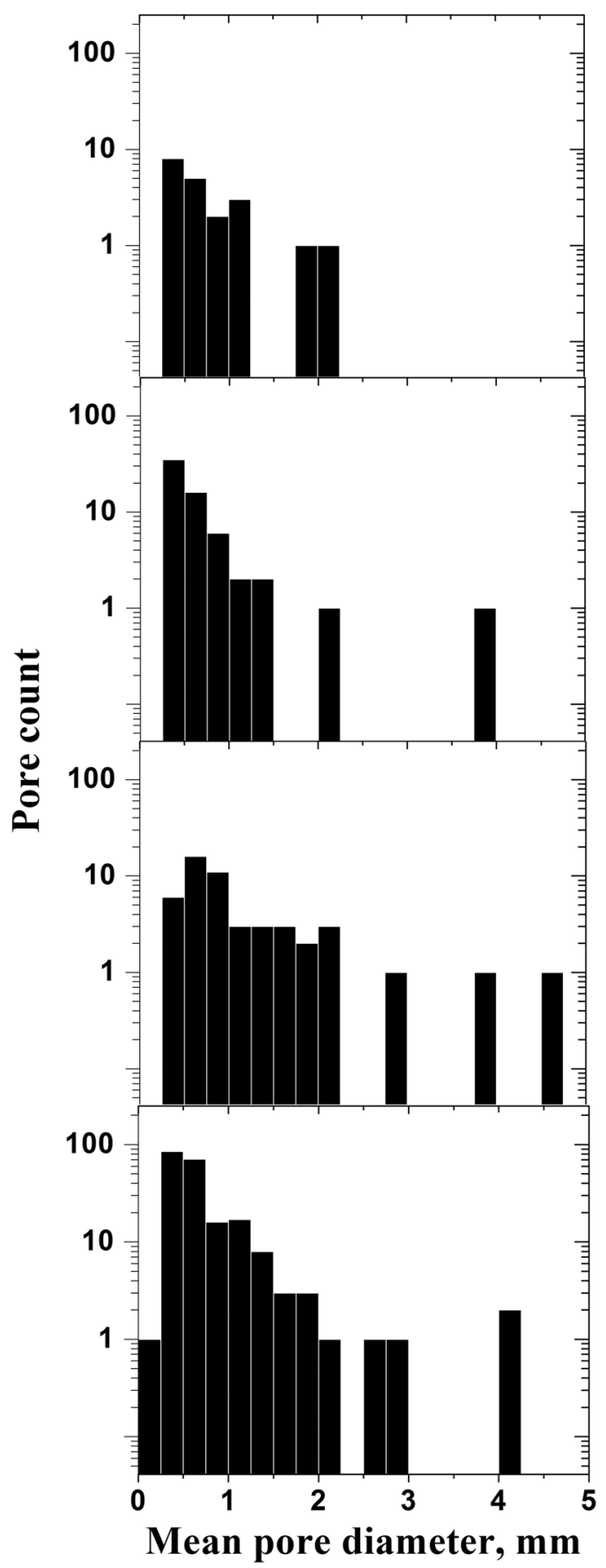

Fig. 3. Effect of the $\mathrm{TiH}_{2}$ to $\mathrm{Al}_{2} \mathrm{O}_{3}$ weight ratio on the pore size and distribution in the 4 pass FSP samples fabricated at $858 \mathrm{~K}$ 


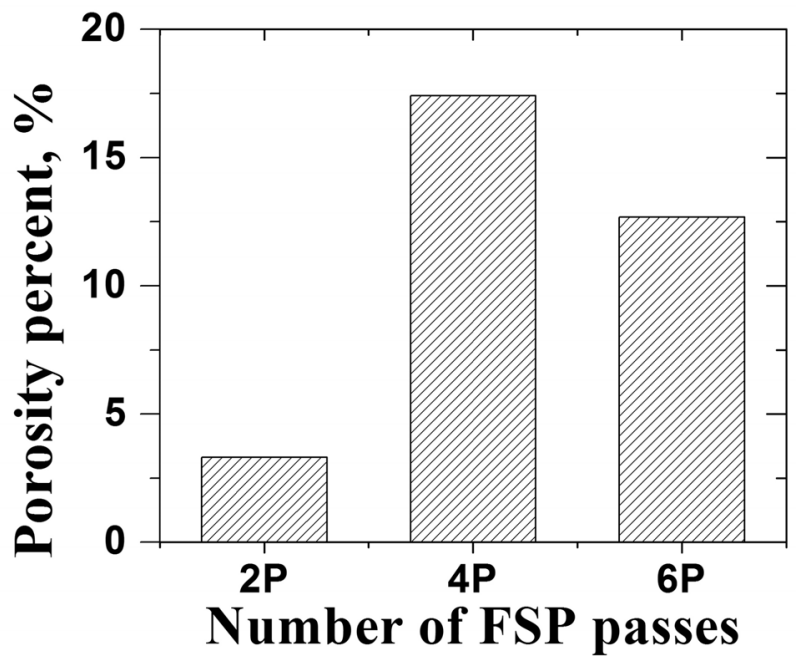

Fig. 4. Variation of porosity in FSP samples with number of FSP passes

four passes of FSP, and heat treated at $858 \mathrm{~K}$. With an increase in this ratio, an increase in porosity and improved pore distribution was observed. Larger pores and a heterogeneous morphology occurred in the samples with a low $\mathrm{TiH}_{2}$ to $\mathrm{Al}_{2} \mathrm{O}_{3}$ weight ratio. In this case, less blowing agent leads to a random pore distribution. Larger pores in the samples with lower $\mathrm{TiH}_{2}$ is due to a higher $\mathrm{TiH}_{2}$ volume in certain places. Therefore, coalescence occurred and large pores were produced due to the short distance between the pores.

As illustrated in Fig. 5, there is a linear relation between porosity and the $\mathrm{TiH}_{2}$ to $\mathrm{Al}_{2} \mathrm{O}_{3}$ weight ratio. This means that more blowing agent leads to formation of more pores. In the present study, the best pore distribution occurred in the samples fabricated using 4-pass FSP, after addition of 5 mass\% $\mathrm{TiH}_{2}$ and 3.5 mass $\% \mathrm{Al}_{2} \mathrm{O}_{3}$, a holding temperature of $858 \mathrm{~K}$, and a holding time of $45 \mathrm{~min}$. As can be seen in Fig. 1, the pore size is lower than $2 \mathrm{~mm}$ and a great portion of pores is lower than $0.2 \mathrm{~mm}$. Fig. 6 , shows these very fine pores and the good $\mathrm{A} 12 \mathrm{O} 3$ nanoparticles distribution which leads to these pore formation.

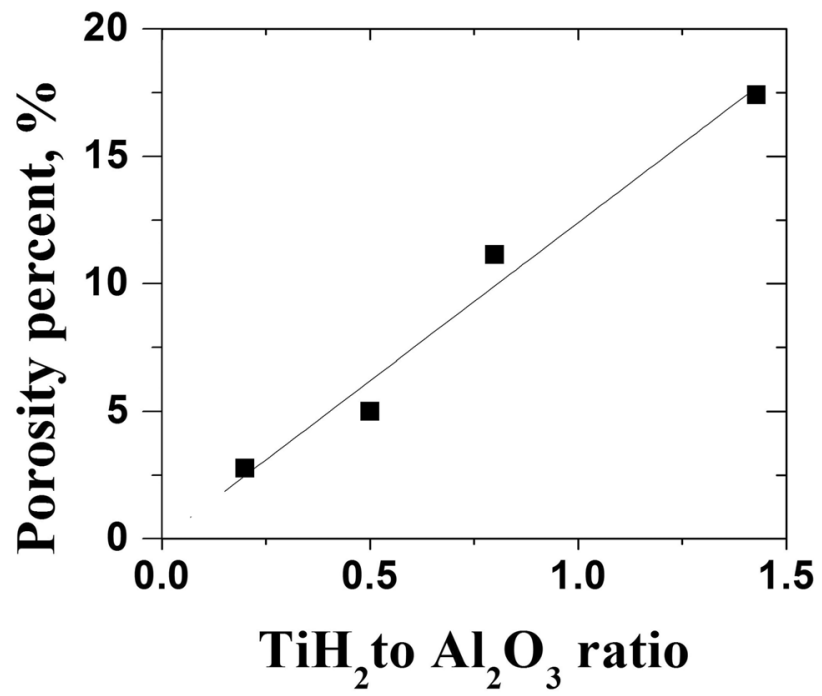

Fig. 5. Variation of porosity in the FSP samples processed with the $\mathrm{TiH}_{2}$ to $\mathrm{Al}_{2} \mathrm{O}_{3}$ weight ratio

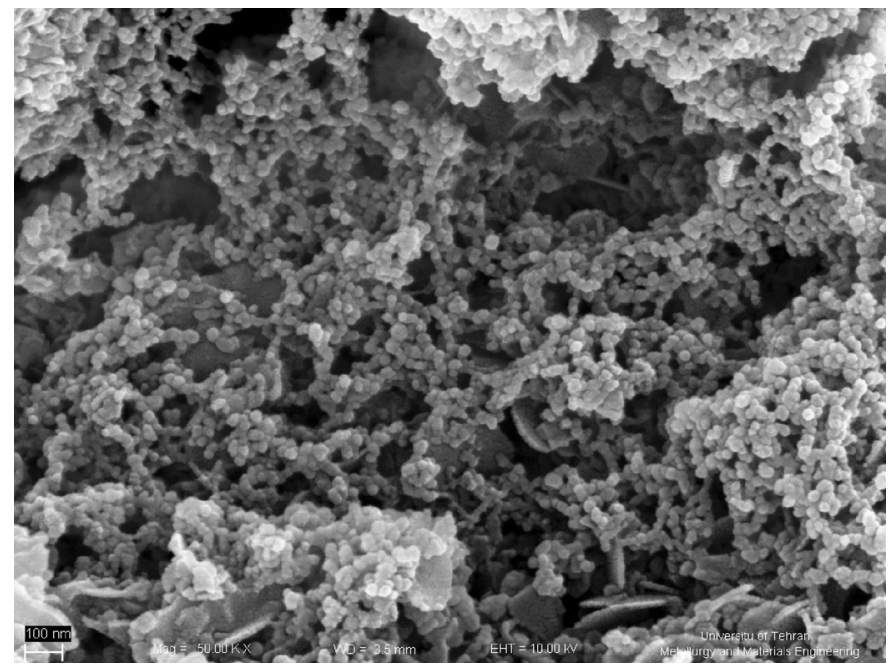

Fig. 6. Scanning electron micrograph of the FSP sample produced under the optimum condition

Figure 7 summarizes the effects of foaming temperature, the $\mathrm{TiH}_{2}$ to $\mathrm{Al}_{2} \mathrm{O}_{3}$ weight ratio, and the number of FSP passes, on the porosity. A similar trend occurred in all the samples. Also, the 4-pass ones had the highest porosity in all the samples. Analysis of these results led to the following empirical equation: $p=A \exp (Q /$ $\mathrm{RT}$ ), where $\mathrm{p}$ is the porosity, $\mathrm{Q}$ is the activation energy of pore formation, $\mathrm{T}$ is the foaming temperature, $\mathrm{R}$ is the gas constant, and $\mathrm{A}$ is a constant. Table 1 shows the $\mathrm{Q}$ and A parameters of this equation. These $\mathrm{Q}$ values are very close to the values in the report by Yang et al. [27], which measured the activation energy of the decomposition of $\mathrm{TiH}_{2}$ powders in argon gas. However, their measured values were slightly lower than those in the present study. This is owing to higher pressure on $\mathrm{TiH}_{2}$ in the foam precursor than on $\mathrm{TiH}_{2}$ powder in argon gas. Yang et al. also reported that the activation energy changed with temperature. On the other hand, due to the close range of heat treatment temperature to that in the present study, the Q value was almost unchanged.

TABLE 1

Activation energy of pore formation and parameter for pore formation

\begin{tabular}{|c|c|c|c|}
\hline & \multicolumn{3}{|c|}{$\mathbf{Q}$ (kJ/mole), A } \\
\hline $\mathbf{T i H}_{\mathbf{2}}-\mathbf{A l}_{\mathbf{2}} \mathbf{O}_{3}$ & 2-pass & 4-pass & 6-pass \\
\hline $5 \%-3.5 \%$ & $\sim 512,5.25 \times 10^{31}$ & $\sim 500,5.25 \times 10^{31}$ & $\sim 502,5.25 \times 10^{31}$ \\
\hline $4 \%-5 \%$ & $\sim 512,3.35 \times 10^{31}$ & $\sim 500,3.35 \times 10^{31}$ & $\sim 502,3.35 \times 10^{31}$ \\
\hline $2.5 \%-5 \%$ & $\sim 512,1.5 \times 10^{31}$ & $\sim 500,1.5 \times 10^{31}$ & $\sim 502,1.5 \times 10^{31}$ \\
\hline $1 \%-5 \%$ & $\sim 512,0.83 \times 10^{31}$ & $\sim 500,0.83 \times 10^{31}$ & $\sim 502,0.83 \times 10^{31}$ \\
\hline
\end{tabular}

\section{Conclusions}

1. In this study, the effect of the number of FSP passes, foaming temperature, and $\mathrm{TiH}_{2}$ to $\mathrm{Al}_{2} \mathrm{O}_{3}$ weight ratio, on the porosity and pore structure of pure magnesium foam fabricated using the FSP-route precursor method was investigated, and the following findings recorded. 


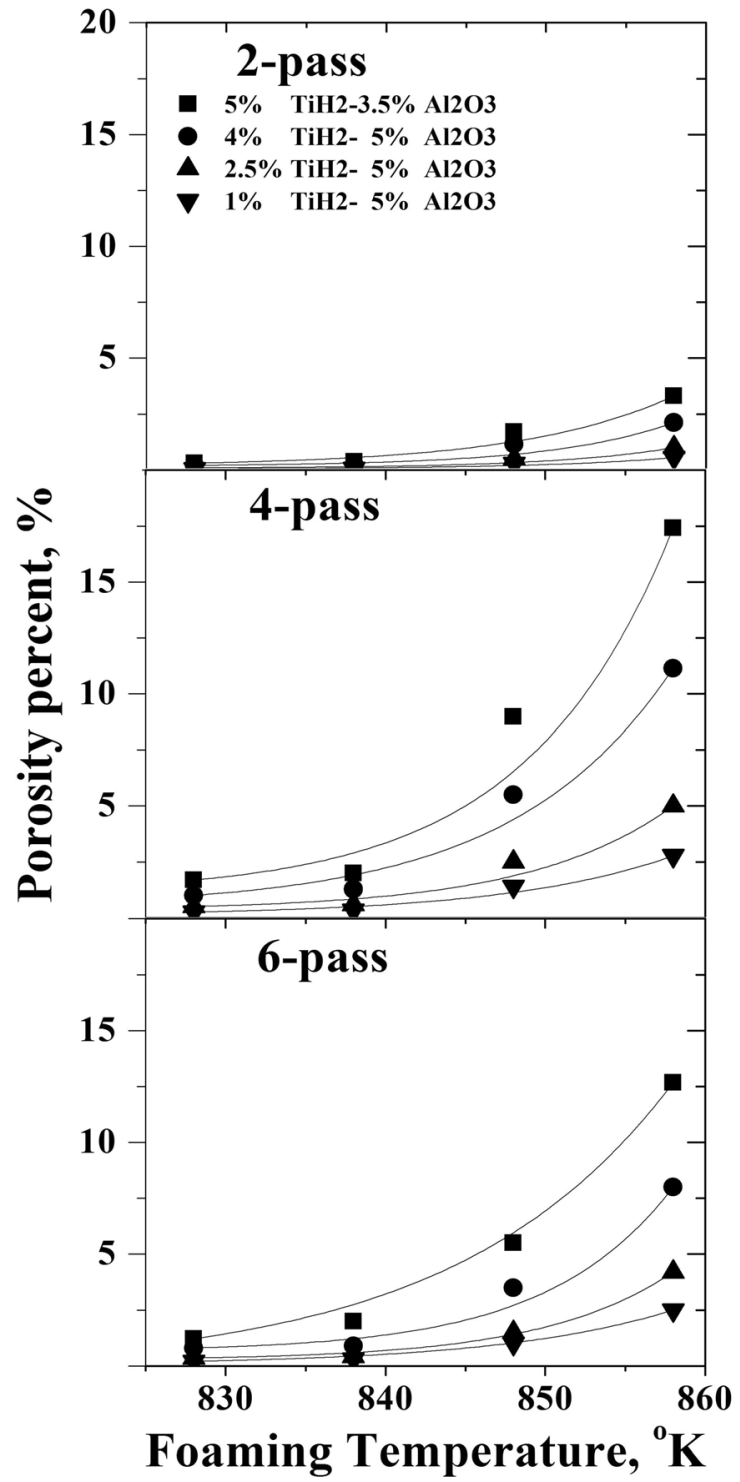

Fig. 7. Effects of Foaming temperature, $\mathrm{TiH}_{2}$ to $\mathrm{Al}_{2} \mathrm{O}_{3}$ weight ratio, and Number of FSP passes on porosity of the FSP samples

2. The porosity of the foam region increased as the holding temperature was increased from 828 to $858 \mathrm{~K}$.

3. Higher porosity magnesium with the uniform pore-size distribution was produced after four passes of FSP. Further FSP passes led to collapse of the pores and a decrease in porosity.

4. With a decrease in the $\mathrm{TiH}_{2}$ to $\mathrm{Al}_{2} \mathrm{O}_{3}$ weight ratio, large pores with heterogeneous morphology were generated.

5. The activation energy of $\mathrm{TiH}_{2}$ decomposition was slightly different in the precursor fabricated with various number of FSP passes.

\section{Acknowledgments}

M. Azizieh, R. Pourmansouri, H. Kafashan and Z. Balak gratefully acknowledge Islamic Azad University, the Ahwaz Branches for financial support towards this research work. In addition, H. S. Kim acknowledges a grant obtained from the National Research Foundation of Korea (NRF) funded by the Korea government (MSIP) (No. 2014R1A2A1A10051322).

\section{REFERENCES}

[1] M.F. Ashby, A.G. Evans, N.A. Fleck, L.J. Gibson, J.W. Hutchinson, H.N.G. Wadley; 'Metal foams: a design guide', 2000, Butterworth-Heinemann, p. 1-23.

[2] C.E. Wen, Y.Yamada, K. Shimojima, Y. Chino, H. Hosokawa, M. Mabuchi, Mater. Lett. 58, 357-360 (2004).

[3] C.E. Wen, M. Mabuchi, Y. Yamada, K. Shimojima, Y. Chino, T. Asahina, Scripta Mater. 45, 1147-1153 (2001).

[4] G.L. Hao, F.S. Han, W.D. Li, J. Porous Mater. 16, 251-256 (2009).

[5] G.L. Hao, F.S. Han, J. Wu, X.F. Wang, Powder Metall. 50, 127131 (2007).

[6] H. Y. Zhuang, Y. Han, A. L. Feng, Mater. Sci. Eng. C 28, 14621466 (2008).

[7] J. Capek, D. Vojtech, Mater. Sci. Eng. C Mater. Biol. Appl. 33, 564-569 (2013).

[8] Y. Yamada, K. Shimojima, Y. Sakaguchi, M. Mabuchi, M. Nakamura, T. Asahina, J. Mater. Sci. Lett. 18, 1477-1480 (1999).

[9] S. Ho, C. Ravindran, G.D. Hibbard, Scripta Mater. 62, 21-24 (2010).

[10] J.H. Xu, G.B. Mao, L.P. Cheng, Z. Q. Hu, 23, 84-87 (2003).

[11] N.T. Kirkland, I. Kolbeinsson, T. Woodfield, G.J. Dias, M.P. Staiger, Mater. Sci. Eng. B Adv. Funct. Solid-State Mater. 176, 16661672 (2011).

[12] M.P. Staiger, I. Kolbeinsson, N.T. Kirkland, T. Nguyen, G. Dias, T.B.F. Woodfield, Mater. Lett. 64, 2572-2574 (2010).

[13] X.C. Xia, W.M. Zhao, X.Z. Feng, H. Feng, X. Zhang, Mater. Des. 49, 19-24 (2013).

[14] Z.G. Xu, J.W. Fu, T.J. Luo, Y.S. Yang, Mater. Des. 34, 40-44 (2012).

[15] X.N. Gu, W.R. Zhou, Y.F. Zheng, Y. Liu, Y.X. Li, Mater. Lett. 64, 1871-1874 (2010).

[16] Y. Hangai, T. Utsunomiya, Metall. Mater. Trans. A 40, 275-277 (2009).

[17] Y. Hangai, T. Utsunomiya, Metall. Mater. Trans. A 40, 1284-1287 (2009).

[18] Y. Hangai, K. Saito, T. Utsunomiya, S. Kitahara, O. Kuwazuru, N. Yoshikawa, Mater. T. JIM 54, 405-408 (2013).

[19] Y. Hangai, T. Utsunomiya, M. Hasegawa, J. Mater. Proc. Tech. 210, 288-292 (2010).

[20] A.F. Hasan, C.J. Bennett, P.H. Shipway, Mater. Des. 87, 1037-1046 (2015).

[21] Y. Hangai, Y. Ozeki, T. Utsunomiya, Mater. T. JIM 50, 2154-2159 (2009).

[22] H. Liu, P. He, J.C. Feng, J. Cao, Int. J. Hydrogen Energ. 34, 30183025 (2009).

[23] K. Kitazono, S. Nishizawa, E. Sato, T. Motegi, Mater. T. JIM, 45, 2389-2394 (2004).

[24] F. Baumgartner, I. Duarte, J. Banhart, Adv. Eng. Mater. 2, 168-174 (2000).

[25] I. Duarte, J. Banhart, Acta Mater. 48, 2349-2362 (2000).

[26] K. Kitazono, E. Sato, K. Kuribayashi, Scripta Mater. 50, 495-498 (2004).

[27] D. Yang, J. Chen, H. Wang, J. Jiang, A. Ma, Z. P. Lu, J. Mater. Sci. Tech. 31, 361-336 (2015). 